\title{
Physiopathological Analysis of MSDs, by Exposure to PDV's in Oil Production Plant Operators
}

\author{
Guillermo Neusa Arenas ${ }^{1 *}$, Jeanette del Pilar Ureña Aguirre², Ramiro \\ Vicente Saraguro ${ }^{3}$, and María Yajairra Galeano Tocain ${ }^{4}$ \\ ${ }^{1}$ Occupational Health Specialist, UTN-Ecuador \\ ${ }^{2}$ Magister in Industrial and Environmental Safety and Hygiene, UTN-Ecuador \\ ${ }^{3}$ Master in Business Administration, UTN-Ecuador \\ ${ }^{4}$ Industrial Engineer, UTN-Ecuador
}

Research Article

Volume 4 Issue 3

Received Date: June 01, 2020

Published Date: June 24, 2020

DOI: $10.23880 /$ eoij-16000241

*Corresponding author: Guillermo Neusa Arenas, Occupational Health Specialist, Universidad Técnica del Norte, IbarraEcuador, postal code: 100105, Ibarra, Ecuador, Email: gneusa@utn.edu.ec; Tel: (+00593) (9) (84942409)

\section{Abstract}

The innovation in office areas and control rooms with new technologies can generate discomfort in the work environment by the use of display screens (PDV's), there are several physiopathologies in the appearance of musculoskeletal disorders (MSD); in a study of 100 operators of a production center of crude oil, were analyzed pathological occupational symptoms such as: right wrist pain, lower back pain, elbow inflammation, pain in the thumb and neck pain, caused in many cases by poor posture or repetition in each cycle of work. When applying the ROSE method, I determine the presence of fatigue and stress, observing the relation of clinical occupational alterations; lumbago $26 \%$, carpal tunnel syndrome $23 \%$, olecranon bursitis $18 \%$, radial styloid tenosynovitis $13 \%$, muscular inflammation $11 \%$, and by degenerative discopathy $9 \%$; the presence of these dysergonomic conditions and, with other successes reached by other authors.

Keywords: Physiopathology; Musculoskeletal Disorder; Pathology; Biometry

\section{Introduction}

The term musculoskeletal disorders (MSD), comprises a series of sets of injuries or symptoms that can affect the entire musculoskeletal system and other associated parts of the body anatomy, causing discomfort in joints, tendons, bones, muscles, ligaments, nerves and even blood vessels. These MSDs, related in the field of work to those induced or indisposed by the cycles of exposure to work, cause unfavorable conditions in the health of the worker [1].

MSDs are one of the main causes related to occupational or professional diseases, which affect many workers in all sectors of industry or production, with considerable expenditure on a nation's economy. Musculoskeletal disorders can have serious short-, medium- and long-term consequences, with damage to the health and quality of life of the worker; thus, permanent pain can lead in many cases to temporary or functional disability [2].

In Spain, according to data from the fifth National Survey on Working Conditions, 4 out of 5 workers show some pain or musculoskeletal discomfort of occupational origin, referring to a pathology or clinical occupational picture, since the frequency of responses may be greater than that corresponding to the lower back, and likewise, the neck and upper part, show a continuous occupational pathological increase in recent years [3].

One of the main objectives of ergonomics is the design of the area and work stations to allow comfort and adapt to the capabilities or limitations of workers, in order to prevent 
possible deterioration in the health and welfare of the individual. Therefore, for MSDs, the design of the workplace must comply with a series of requirements that protect the worker from the beginning of the workday. These designs are centralized from the normal, with a change both integral or partial according to the area or space of the work place or the task to be performed, taking into account the equipment, machines or tools to be used during the cycles of exposure to the work. In this way, the importance of improvement and adequate training should be emphasized, once the improvements in the conditions favourable to work have been implemented [4].

In the ergonomic evaluation there are several types of methods such as: RULA, LEST, MAPFRE, Check-List OCRA, EWA, OWAS, SNOOK, among others, which allow to determine the needs for both specific conditions by activity that is valued in each worker. However, it is necessary to point out its results at the moment of obtaining the application of the specific method, it is only a question of formulating a point of review at the level of approach. Therefore, when identifying the risk factor to which the worker is exposed, the theory as well as the processes in the production and the methods that are these technicians for their evaluation, will depend on the current working conditions in the worker's organization so that he/she can develop his/her activity in the best way.

The POS, like any tool, can cause a deterioration in health over time by not taking appropriate control and preventive measures in use. Nevertheless, the own work scenarios for the use of computer or other visualization equipment must be taken into account. In this sense, there are standards and associated techniques for the proper use of POS [5].

For this reason, putting theoretical knowledge into practice involves a series of fields of activity for the worker. Although, the types of actions will depend much on the proposed objectives and the interest of the organization, which, in such a way, are important to generate a conscience and culture of responsibility and understanding, valuing a systematic direction from the theory based on the prevention of MSDs.

In terms of hygiene and occupational health, it is necessary to establish controls of physiopathologies due to MSDs, keeping records of preventive occupational medicine, maintaining a clinical history per worker during periods of exposure by cycles of time of exposure, in order to carry out occupational epidemiological monitoring.

\section{Materials and Methods}

In recent decades the rapid spread of new technologies of the 21st century, have achieved growth in all productive sectors in organizations, where operators of CPFs who spend more than six hours a day in front of POS. However, we can consider that they are users with health risk, with possible damages or injuries that can be associated to the acute use of the PDV's, increasing the occupational clinical pathologies [6].

From the beginning of the research, several methodological aspects are analyzed that allow a subjective analysis in each of the areas and jobs by the operator of the Oil Production Plants, also called Production Centers and Facilities-CPF (Figure 1). Each of the biomechanical movements of the body is evaluated by its exposure.

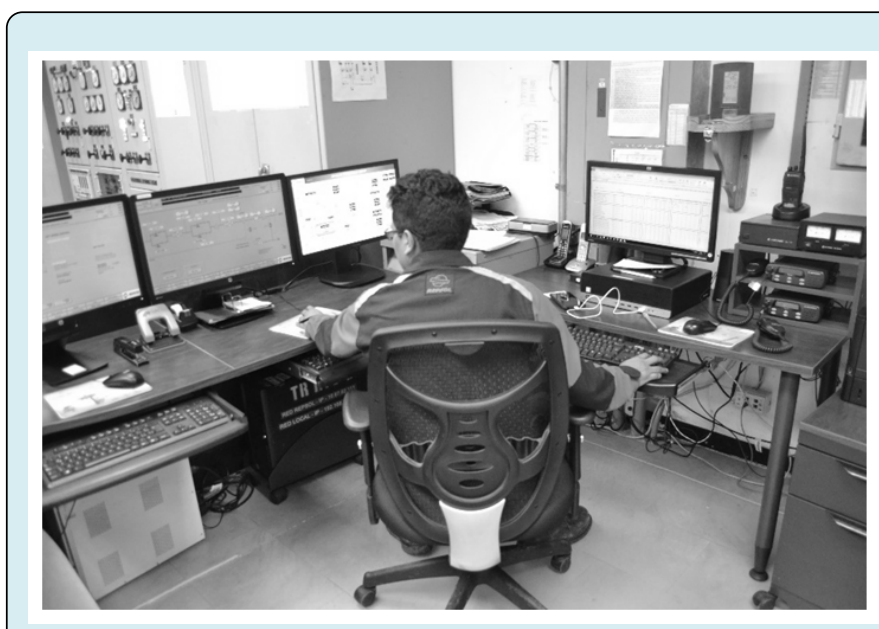

Figure 1: Use of POS in the CPF control room. Source: (H.0., 2019).

Therefore, the form and nature of workin the organization by task during the cycles and rotation, are observed based on the Nordic questionnaire, videos, photographs, tools for identification, control and postural evaluation through the ROSA (Rapid Office Strain Assessment) Method [7].

By using a survey to identify the main physical discomforts present in the operators, the health risk factors that are so minimal or appear to be non-routine or routine, such as the location of the monitor at a certain distance or the angle that they may be inadequate; "other associated factors in office areas or control centres, is the comfort that can contribute to the risk such as temperature, incorrect environmental relative humidity and lighting, which can generate health effects [8].

\section{Sample and Population}

The population of 330 corresponds to operators, 
integrated in different areas or jobs. The size of the finite research sample was determined for the study. In Table 1, the variables for the application of the sample size formula are established [9].

\begin{tabular}{|c|c|}
\hline \multicolumn{2}{|c|}{ Data } \\
\hline$Z$ & 1,96 \\
\hline$P$ & $50 \%$ \\
\hline$Q$ & $50 \%$ \\
\hline$N$ & 330 \\
\hline$D$ & $8 \%$ \\
\hline
\end{tabular}

Table 1: Sample variable.

When establishing the sample (330 Oper.), it is necessary to know the equation; the calculation of the finite sample is represented in

$$
\begin{gathered}
n=\frac{N * Z_{a}^{2} p^{*} q}{d^{2} *(N-1)+Z_{a}^{2} * p^{*} q} \\
n=\frac{330 * 1,96^{2} * 0,5 * 0,5}{0,08^{2} *(330-1)+1,96^{2} * 0,5 * 0,5} \\
n=\frac{330 * 3,84 * 0,25}{0,0064 * 329+3.84 * 0,25} \\
\mathrm{n}=103
\end{gathered}
$$

The sample size of $103 \mathrm{CPF}$ operators is the size of the target group.

\section{Population Observation}

The information was collected according to the finite sample size of 103 operators and, through the Nordic Questionnaire survey determining musculoskeletal disorders (MSDs), constituting one of the most frequent and costly health problems in the occupational field worldwide. "Early detection of pathological symptoms by initial EMDs is a priority for epidemiological surveillance programmes" [10].

On the other hand, other aspects should be taken into account, such as: age and sex ranges (Table 2. and in Graph 1, graphic representation by age), which allow the establishment of pathologies by MSDs; Likewise, another point of view, embodied in Table 3, is the identification of work areas and jobs.

\begin{tabular}{|c|c|c|}
\hline Prom. Age & Men & Women \\
\hline $20-25$ & 15 & 7 \\
\hline $26-35$ & 21 & 4 \\
\hline $36-30$ & 29 & 2 \\
\hline $31-49$ & 14 & 2 \\
\hline $50-+$ & 9 & 0 \\
\hline Subtotal: & 88 & 15 \\
\hline Total: & 103 & \\
\hline
\end{tabular}

Table 2: Age ranges.

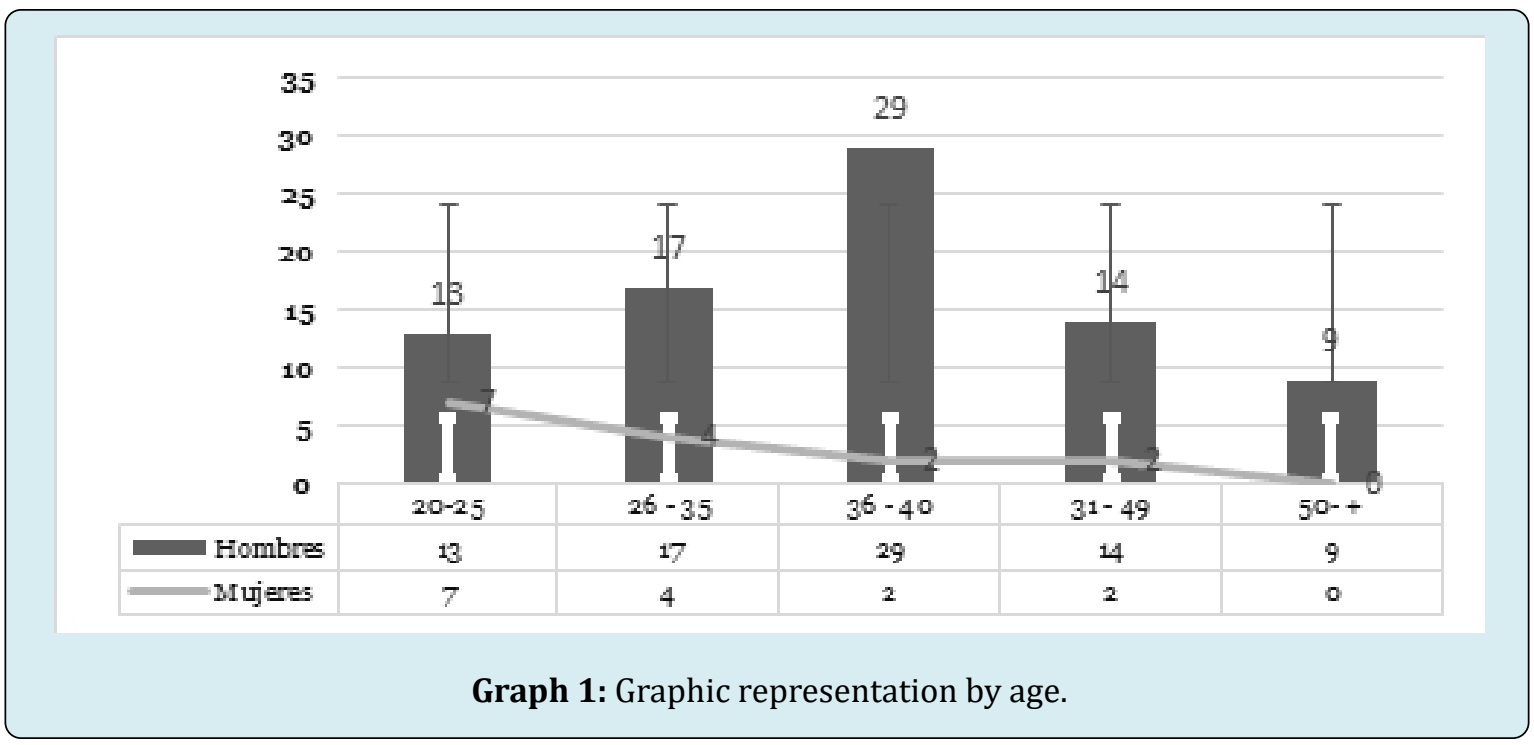




\begin{tabular}{|c|c|c|}
\hline Area & Operators & $\mathbf{\%}$ \\
\hline Warehouses & 2 & $2 \%$ \\
\hline Energy & 18 & $17 \%$ \\
\hline Maintenance & 47 & $46 \%$ \\
\hline Operations & 1 & $1 \%$ \\
\hline Production & 23 & $22 \%$ \\
\hline P and O & 5 & $5 \%$ \\
\hline RRCC & \multicolumn{2}{|c|}{2} \\
\hline SMA & 3 & $3 \%$ \\
\hline Ti & 2 & $2 \%$ \\
\hline Total & 103 & $100 \%$ \\
\hline
\end{tabular}

Table 3: Area and Distribution of operators is identified, according to the selected sample size.

\section{Relationship between the ROSE Method and the Nordic-CN Questionnaire}

Based on the CN the MSD symptoms were applied with the purpose of determining the analogy between the operator's musculoskeletal symptoms with elements of the workplace with PDV's. Therefore, the descriptive method of correlation is analysed, using the Excel program and Ergo Soft Pro-5.0 taking scores from the ROSA method and the CN constants. In the scoring of the chair, the biometric part of the upper back, as well as the lower back, shoulders, thighs and hips corresponded; also, the use of the monitor and the phone with neck hook. In the upper back, the mouse and keyboard with shoulder tilt; while, the upper arm and wrist, establish a final score of the $\mathrm{CN}$ method; determining the most representative MSDs in each of the operators.

\section{ROSE Evaluation Method}

"The POS is a work tool that can cause severe damage to the health of workers over time if adequate preventive measures are not taken in time" [11].

In studies conducted on practices for exposure to PDV's, the ROSA method (Rapid Office Strain Assessment), published by Sonne and Andrews in Applied Ergonomics [7]; was applied in the research project in the crude oil production plants at $\mathrm{CPF}$, identifying the intervention areas in the offices and control rooms (Control Rum), through the cycles of exposure per minute and postural anthropometric parameters such as:

- Form of sitting posture.

- Technical characteristics of the seat.

- Use and geometric height between the base line (desk) and the height of the monitor, keyboard and telephone.

- Duration of exposure during the working day.

- Rating of scores between 1 and 4, scores above 5, is considered a factor in high risk [12].

\section{Results}

\section{Representation of the Population}

In the analyses carried out on 103 operators in the CPF of the oil sector in Ecuador and, taking into account the characterization by the operators of: $72.7 \%$ men and $27.3 \%$ women, with an average age of $36-40$, an average time in the oil sector between 4 and 17 years, and a size in the operators of 1.64, and, in the operators 1.48 .

\section{Analysis and Interpretation}

Based on the surveyed $\mathrm{NC}$, it is shown that $49.3 \%$ carried out activities involving cargo handling and transport before joining the company and, $50.7 \%$ of the operator's state that they have no relation with other activities of this nature.

Table 4 shows the incidence of the most common MSD physiopathologies in the operators of the different areas during the last 12 months, with occupational medical care.

\begin{tabular}{|c|c|c|c|}
\hline \multicolumn{1}{|c|}{ Area } & Workplace & Risk level & Clinical Pathologies \\
\hline Human resources & $\begin{array}{c}\text { Manager people and organizations and social } \\
\text { work }\end{array}$ & High & $\begin{array}{c}\text { Olecranon bursitis } \\
\text { Degenerative Discopathy } \\
\text { Lumbago } \\
\text { Carpal Tunnel Syndrome } \\
\text { Production }\end{array}$ \\
& Production engineering & Hadial styloid tenosynovitis \\
\hline & & $\begin{array}{c}\text { Olecranon bursitis } \\
\text { Degenerative Discopathy } \\
\text { Inflammation of muscles } \\
\text { Lumbago } \\
\end{array}$ & $\begin{array}{c}\text { Carpal Tunnel Syndrome } \\
\text { Radial styloid tenosynovitis }\end{array}$ \\
\hline
\end{tabular}




\begin{tabular}{|c|c|c|c|}
\hline Human resources & Administrative assistant & High & $\begin{array}{c}\text { Olecranon bursitis } \\
\text { Lumbago } \\
\text { Carpal Tunnel Syndrome } \\
\text { Radial styloid tenosynovitis }\end{array}$ \\
\hline Energy & Generation operator & Medium & $\begin{array}{c}\text { Olecranon bursitis } \\
\text { Lumbago } \\
\text { Carpal Tunnel Syndrome }\end{array}$ \\
\hline Production & Production operator & Medium & $\begin{array}{c}\text { Olecranon bursitis } \\
\text { Inflammation of muscles } \\
\text { Carpal Tunnel Syndrome }\end{array}$ \\
\hline Maintenance & Static maintenance coordinator & Medium & $\begin{array}{c}\text { Degenerative Discopathy } \\
\text { Inflammation of muscles } \\
\text { Lumbago } \\
\text { Carpal Tunnel Syndrome }\end{array}$ \\
\hline TI & Technical support TI & Medium & $\begin{array}{c}\text { Inflammation of muscles } \\
\text { Lumbago } \\
\text { Carpal tunnel syndrome Radial } \\
\text { styloid tenosynovitis }\end{array}$ \\
\hline
\end{tabular}

Table 4: Most common MSD physiopathologies.

While Table № 5, on identifying the physiopathologies due to MSDs on average and according to $\mathrm{CN}$ results and the ROSA Method, in the most infectious ones it was determined that; by dorsolumbar spine $68.4 \%$ of the operators have had pain in the dorsolumbar spine, cervical spine, arms or forearms, shoulders, hands or wrists, knees, ankles or feet; on the other hand, $38.7 \%$ have not presented occupational clinical pictures (OCC) of any type of ailment in the last six months.

\begin{tabular}{|c|c|c|}
\hline $\begin{array}{c}\text { Have you suffered any } \\
\text { problems or pain? }\end{array}$ & Yes & No \\
\hline Cervical Column & 67,7 & 32,3 \\
\hline Dorsolumbar spine & 68,4 & 31,6 \\
\hline Shoulders & 53,8 & 46,2 \\
\hline Arms or forearms & 39,9 & 60,1 \\
\hline Hands or wrists & 49,3 & 50,7 \\
\hline Knees & 33,5 & 66,5 \\
\hline Ankles or feet & 27,3 & 72,7 \\
\hline Average & 48,6 & 51,4 \\
\hline
\end{tabular}

Table 5: Identifying the physiopathologies due to MSDs.

Among the most common occupational clinical pictures of MSDs manifested by operators during the work cycles are forced postures with frequent consequences, inducing improvement measures from physical therapy, medication, rest, intervention, occupational medicine and rehabilitation.

\section{Occupational Medical Care}

In the occupational medical assessments for periodic MSDs, it was possible to identify osteomuscular pathologies considered as chronic conditions, caused in a direct way by exposure during the work cycles, producing temporary and periodic disability.

Table 6 shows the frequency of occupational health care personnel during the last six months.

\begin{tabular}{|c|c|c|}
\hline Alternatives & Frequency & Percentage \\
\hline General practitioner & 43 & $42 \%$ \\
\hline Others & 31 & $30 \%$ \\
\hline None & 29 & $28 \%$ \\
\hline Total & 103 & $100 \%$ \\
\hline
\end{tabular}

Table 6: Frequency of occupational health care in last six months.

\section{Preventive Medicine Analysis}

In Table 7, the analyses of preventive occupational medicine for MSDs, provided to operators, have clinical osteomuscular pictures in relation to the work in the PDV's such as: dorsalgia, lumbago, shoulder alterations, cervicalgia, carpal tunnel syndrome, epicondylitis and tendinitis. However, in the majority of cases, rotator cuff and bicipital tendonitis such as bursitis, Quervain's tenosynovitis, carpal tunnel syndrome, lateral and medial epicondylitis, produce 
a clinical occupational picture due to disc and lumbar hernia pain.

\begin{tabular}{|c|c|c|}
\hline Alternatives & Frequency & Percentage \\
\hline $\begin{array}{c}\text { Musculoskeletal } \\
\text { disorders }\end{array}$ & 26 & $58 \%$ \\
\hline Inflammations & 10 & $22 \%$ \\
\hline Other conditions & 9 & $20 \%$ \\
\hline Total & 45 & $100 \%$ \\
\hline
\end{tabular}

Table 7: Analyses of preventive occupational medicine.

\section{Occupational Medical Treatment}

Table 8 shows the different occupational medical treatments for MSDs carried out on operators, and provides pathological follow-up by ailments or clinical pictures present during the year, related to the frequency of occupational medical care.

\begin{tabular}{|c|c|c|}
\hline Alternatives & Frequency & Percentage \\
\hline Physiotherapy & 12 & $29 \%$ \\
\hline Medication & 14 & $33 \%$ \\
\hline Rehabilitation & 16 & $38 \%$ \\
\hline Total & 42 & $100 \%$ \\
\hline
\end{tabular}

Table 8: Different occupational medical treatments.

\section{Conclusion}

The physiopathological liking for MSD to PDV exposures in CPF field operators, and as a response to the CCOs present in the control room and office area in the population studied, a final score is determined both in the control room and in the offices, between the $\mathrm{CN}$ and the scores obtained by the ROSA method, the osteomuscular symptoms in the neck and lower back. These results of the evaluation, showed that a part of the operators, rise to a high risk level, compared to other positions by medium and long time work cycles, qualifying as high or very high risk level.

$51.4 \%$ of the total number of operators evaluated had a high risk level rating, as determined by the control room analysis and results, while office activities presented $48.6 \%$ due to exposure to the dysergonomic risk factor. However, the highest percentage and agreement among the evaluated areas (both 1 and 2 - in situ), given that they did not present the same conditions for the evaluation, as among the evaluators 1 (control room), 2 (offices) and 3 the applicable ROSA method, was demonstrated with the use of the Excel program and ErgoSoft Pro-5.0 (as a reliable and efficient tool) the evaluation of the workstations with PDV's, reducing the risk factor to improve the comfort of the work area environment as well: seat back, arm advancement zone, precision zone, minimum and maximum reach, right hand grip zone, right and left hand comfort, and the left hand zone for telephone use as shown in the figure 1.

Finally, the intervention by the occupational medicine to be performed, should be of medical control in occupational health and the ergonomist of the company, who will have the need to establish an occupational health program with emphasis on specific examinations of spine $\mathrm{x}$-ray and carpal tunnel syndrome; also, institute training in awareness of bad posture, proper use of furniture and active breaks every 5 minutes according to the cycles of tasks to be performed.

Annex 37: Active Pause Guide

\begin{tabular}{|c|c|}
\hline \multirow{3}{*}{ Active Pause Guide } & Versión: 01 \\
\hline & Code: \\
\hline & Date: $08 / 01 / 2020$ \\
\hline Object: & Establish the main characteristics to be considered in the design of the office workstation. \\
\hline Responsible: Direct: & General Manager \& Plant Manager \\
\hline Methodology: & $\begin{array}{l}\text { Photocopy of the general risk assessment and the evaluation by job Procedures for carrying out } \\
\text { the activities according to the job }\end{array}$ \\
\hline Material Resources: & Laptop or Desktop computer, camera, printer, office supplies (sheets, file cabinets, printer ink) \\
\hline Legal basis: & Executive Decree 2393 \\
\hline
\end{tabular}




\begin{tabular}{|c|c|c|}
\hline Recommendation & Indication & Reference Image \\
\hline Head movements & $\begin{array}{l}\text {-Stay on your feet. } \\
\text {-Place your arms back between } \\
\text { your hands, holding your wrist } \\
\text { with your right arm. } \\
\text {-Tilt your head to the right and } \\
\text { then to the left as if touching your } \\
\text { shoulder. } \\
\text {-Repeat the exercises for } 30 \\
\text { seconds. }\end{array}$ & \\
\hline Arm and wrist movement & $\begin{array}{l}\text {-Stay on your feet. } \\
\text { - Put your arms down open. } \\
\text { - Make a circular motion with } \\
\text { your wrists, from the inside to } \\
\text { the outside and vice versa. } \\
\text { - Repeat the exercises for } 30 \\
\text { seconds. }\end{array}$ & \\
\hline Arm and wrist movement & $\begin{array}{l}\text {-Stay on your feet. } \\
\text { - Put your arms up. } \\
\text { - Join hands and interlock fingers. } \\
\text { - Place your arms above your } \\
\text { head. } \\
\text { - Repeat the exercises for } 30 \\
\text { seconds. }\end{array}$ & \\
\hline Arm movement & $\begin{array}{l}\text {-Stay on your feet. } \\
\text { - Put your arms up. } \\
\text { - With your right arm, press the } \\
\text { elbow of your left arm, bending } \\
\text { your left forearm toward your } \\
\text { back. } \\
\text { - Make a small inward pressure } \\
\text { three times, then switch arms } \\
\text { and repeat the above movements. } \\
\text { - Repeat the exercises for } 30 \\
\text { seconds. }\end{array}$ & \\
\hline Movement of hands & $\begin{array}{l}\text {-Stay on your feet. } \\
\text { - Join the palms of your hands, } \\
\text { with your arms bent. } \\
\text { - Make movements from the } \\
\text { bottom to the top and vice versa. } \\
\text { - Repeat the exercises for } 30 \\
\text { seconds. }\end{array}$ & \\
\hline
\end{tabular}




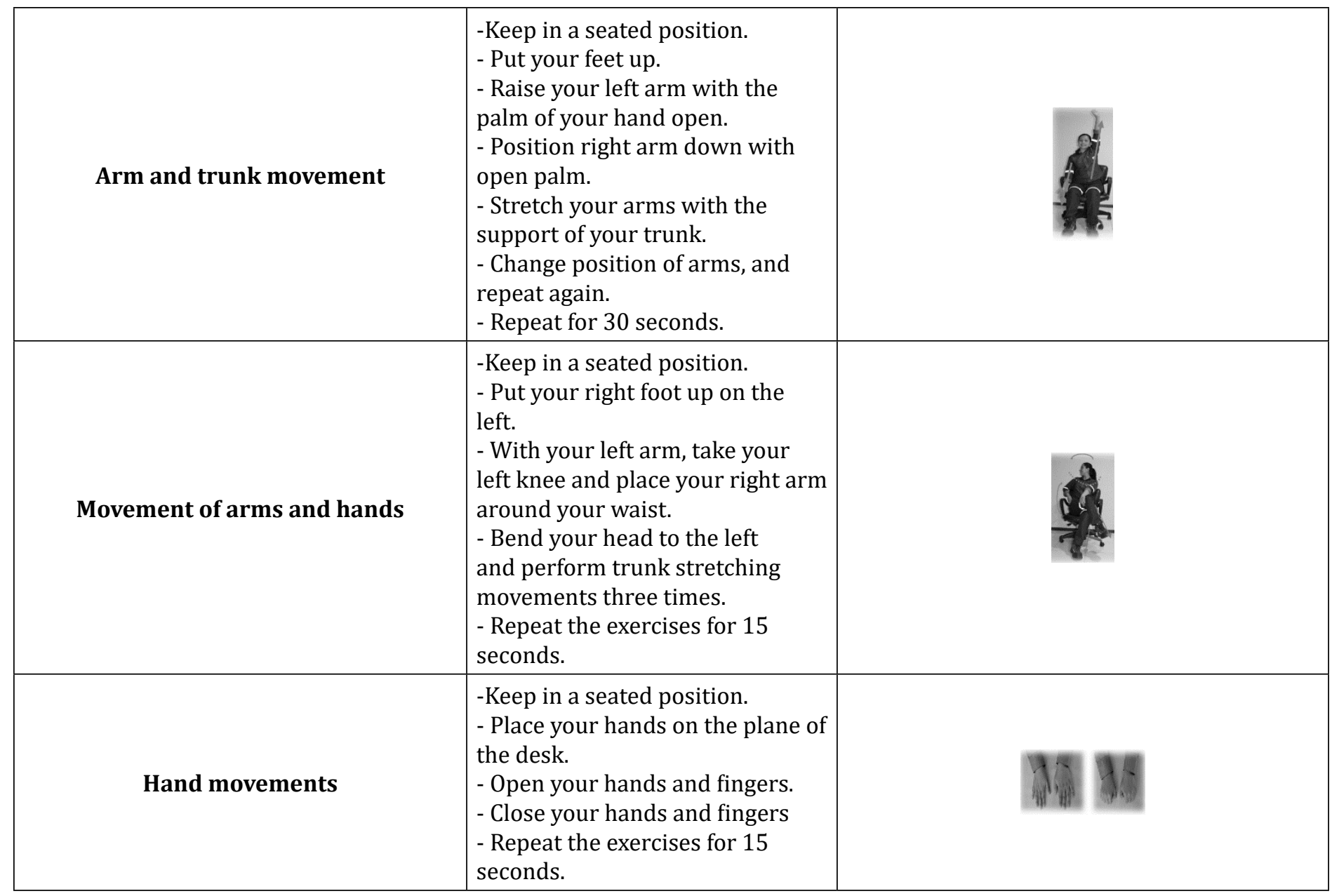

\section{References}

1. Andalucia JD (2014) Brief Guide to the Prevention of Musculoskeletal Disorders at Work-12 (page 5), Junta de Andalucia, Madrid.

2. Álvarez-Casado E (2009) Risk Assessment Manual for the Prevention of Musculoskeletal Disorders. In: Humans F Ed, Trad E, (Eds.), Factors Humans, Barcelona $\mathrm{FC}$, Spain.

3. Hernández-Soto A (2009) Risk Assessment Manual for the Prevention of Musculoskeletal Disorders. In A. Hernández-Soto, Manual de Evaluación de Riesgos para la Prevención de Disordos Musculosqueléticos (page 21). Factors Humans, Barcelona.

4. INSHT (2017) Prevention of Musculoskeletal Disorders in the Health Sector (p. 4), INSHT, Madrid.

5. Arenas GN (2019) The Data Visualization Screens, Gestión de la Ergonomía Laboral en las MYPIMES (págs.
192-202). UTN, Ibarra-Ecuador.

6. Mondelo PR (2005) Ergonomics 4, Elm Office Work. Working with Data Display Screens (DSPs). Alfaomega, Barcelona, Spain, pp: 33-37.

7. Sonne M (2011) ROSA Methodology. The Rapid Office Strain Assessment (ROSA), Hamilton: Canada, pp: 98108.

8. Muñoz JE (2015) Basic Ergonomics, Factores del Entorno y Ambientes. Ediciones de la U, Bogotá, Colombia, pp: 155-156.

9. Morales-Vallejo P (2012) Finite sample size. Applied statistics, pp: 22-39.

10. Martinez MM (2017) Validation of the Standardized Nordic Questionnaire of Musculoskeletal Symptoms for the Chilean Working Population, Adding a Scale of Pain. Public Health Journal 21(2): 41-51. 
11. Guillermo N (2019) Gestión de la Ergonomía Laboral en la MIPYMES (Management of labour ergonomics in MSMEs). UTN, Ibarra.
12. Hurtado V, Londoño N, Lozano S (2016) Validation of the ROSA method in a company with computer work in Medellín, University of Antioquia, Medellín, Colombia. 